\title{
Microcontroller and Gsm Based Windmill Monitoring System
}

\author{
M. Mohanraj, S.Premkumar
}

\begin{abstract}
This paper deals with the design and development of embedded system using GSM technology. The developed instrument is installed in the windmill. An interfacing GSM module is also added to the microcontroller to send the message to windmill owners mobile. The energy/power produced in the windmill is displayed on the energy meter. The energy meter reading is a digital code which will be fetched out by parallel cable and sent to microcontroller and it is transmitted to mobile using GSM module. The controller checks for the valid input code sent from the phone, if the code is valid the data is sent to the concern mobile phone.
\end{abstract}

Keywords—gsm; microcontroller; windmill; embedded system; energy meter;

\section{INTRODUCTION}

The GSM (Global System for Mobile Communications) is one of the famous and world-wide accepted standard for mobile phones, which has an operating frequency of 900 MHz.The speciality of GSM lies in easing out international calls thereby helping the subscribers to access from any parts of the world. Since the channels are of digitized format the signaling and speech clarity are of great quality when compared with their predecessors. GSM, the present Third Generation (3G) system can be used for Wind Mill monitoring most effectively.

\section{II.EASE OF USE}

\section{A.Components}

1. PIC Microcontroller (16F877A).

2. DC Power supply unit.

3. GSM Modem.

4. GSM Mobile.

5. Connecting wires.

6. Receiving antenna.

\section{B.Micro-controller Unit}

A powerful (200 ns) yet easy to program CMOS FLASH based 8-bit microcontroller packs Microchip's powerful PIC $尺$ architecture into an 40 or 44 pin package and is upwards compatible with the PIC16C5X, PIC12CXXX and PIC16C7X devices. The PIC16F877A features 256 bytes of EEPROM data memory, self programming, an ICD, 2 Comparators, 8 channels of 10-bit Analog-to-Digital (A/D) converter, 2 capture/compare/PWM functions, the synchronous serial port can be configured as either 3-wire Serial Peripheral Interface $\left(\mathrm{SPI}^{\mathrm{TM}}\right)$ or the 2-wire Inter-
Integrated Circuit $\left(\mathrm{I}^{2} \mathrm{C}^{\mathrm{TM}}\right)$ bus and a Universal Asynchronous Receiver Transmitter (USART). All of these features make it ideal for more advanced level A/D applications in automotive, industrial, appliances and consumer applications.

\section{Power Unit}

The following are the components used for the DC regulated power supply.

1. $230 \mathrm{~V} / 12 \mathrm{~V}$ step down Transformer.

2. Bridge Rectifier with 4 x 1N4007 diodes.

3. $470 \mu \mathrm{F} / 35 \mathrm{~V}$ Capacitor as a Filter.

4. 7805 Voltage Regulator IC.

The input line voltage is stepped down using the transformer and the output voltage is given to the rectifier Semiconductor diode is used as a rectifier, which helps in converting the ac voltage into pulsating dc voltage. A filter circuit is used to reduce the pulsations in dc voltage. In this circuit, the filter used is a capacitor. The filtered dc output is then fed to a voltage regulator stage. It helps in maintaining a constant output voltage, in addition to smoothing. Here, IC 77805 is employed as a voltage regulator which provides an output voltage of $5 \mathrm{~V}$.

\section{Assembly}

From the block diagram our assembly can be easily understood. First is the windmill in which electricity is produced. This data is sent to the Energy Meter Display. From that display through Parallel Port the Microcontroller is connected. The Microcontroller is connected with the GSM Module. Communication is done between the Mobile and the GSM Module.

\section{GSM Mobile and Antenna}

A handset with simcard facility to send code to GSM modem and to receive a message about the status of the windmill by message sent by the controller. Antenna is connected to the GSM board to receive a message from cell phone.

\footnotetext{
Revised Manuscript Received on 14 August, 2019.

Dr M.Mohanraj, Associate Professor :Dept of EEE, Kumaraguru College of Technology, Coimbatore, Tamilnadu, India.(Email: mohanraj.m.eee@kct.ac.in)

S.Premkumar, PG Scholar:Dept of EEE, Kumaraguru College of Technology, Coimbatore, Tamilnadu, India.(Email:
} prem.16mpe@kct.ac.in).

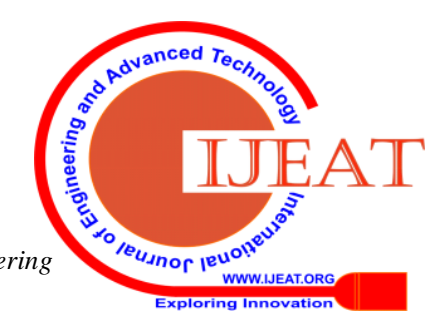




\section{Block Diagram}

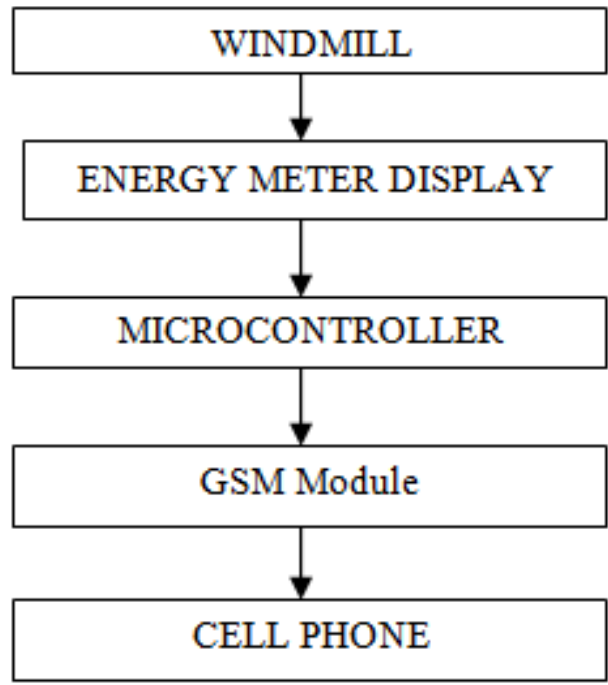

\section{Working\&Results}

The main concept of the project is introduce mobile communication into embedded system. The windmill produces the electrical energy. There are two modes of operation in a windmill. Two generators are used for production of energy. One is for low speed winds and the other is for high speed winds. Now the energy produced is sent to the display meter in the windmill.

The display meter is a device in which it shows the energy generated in the windmill and the rate at which the windmill produces energy. The windmill can be manually overridden using that device. This not only shows the energy produced it also shows if any error occurs in the system. The module which we are building is interfaced to the display meter of the windmill. The display meter has a parallel port so a parallel interfacing is done in it. The data is received from the display meter through the parallel port. The received data is sent to the Microcontroller. The controller which we use here is a PIC controller. The controller reads the data. The GSM module is connected with the controller. The GSM module is further connected with the receiving antenna. When a valid data is sent from the mobile phone it is received by the antenna which sends the requested data to the GSM module. If it's a valid data the requested data is sent to the GSM module by the controller and the GSM module sends it to the mobile phone. Energy produced every 2 hours can be sent automatically or can be requested manually by the person. As some additional features we can also program it to send the errors occurring in the system. This is the working of the system.

\section{Working Model}

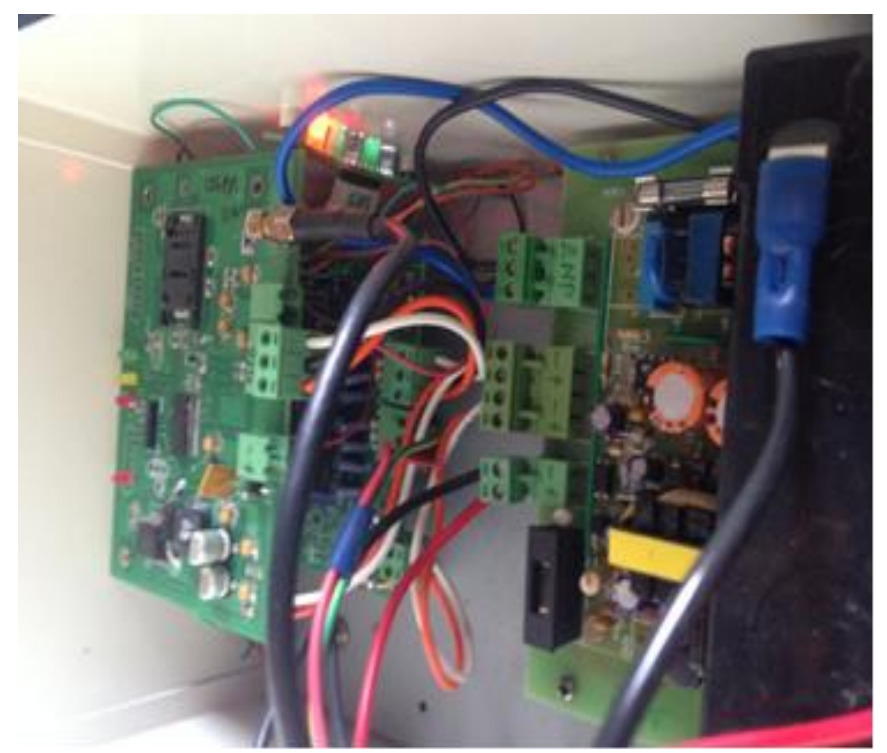

Fig 1 Experimental Setup

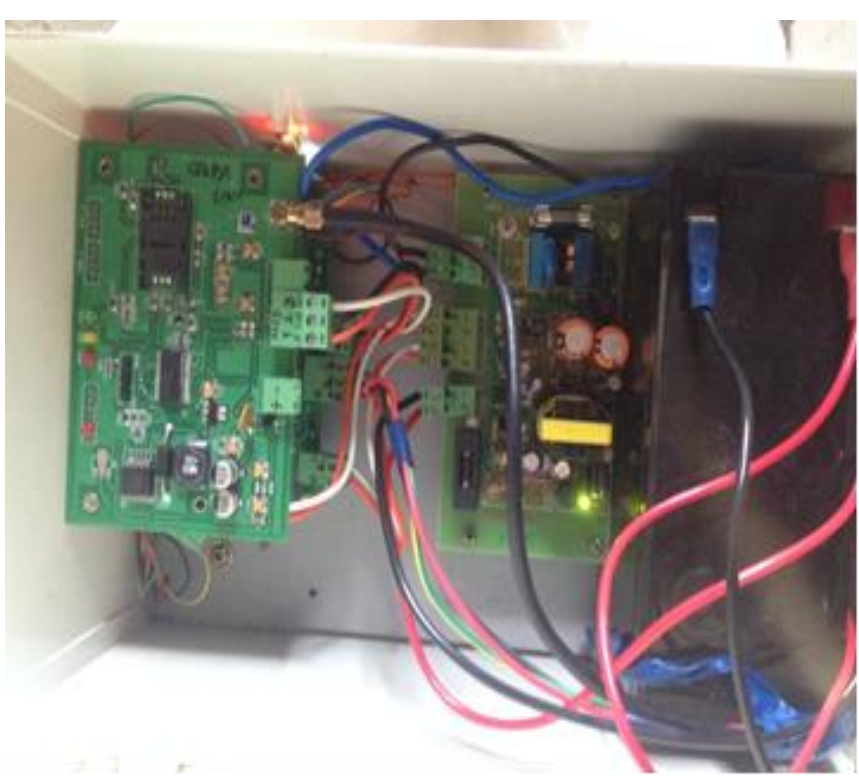

Fig 2 Experimental Setup

\section{ABBREVIATION}

MCUMicrocontroller Control Unit

PICPeriperal Interface Controller

GSM Global System For Mobile Communication

ROMRead Only Memory

RAMRandom Access Memory

CMOSComplementary Metal Oxide Semiconductor

RISCReduced Instruction Set Computation

PCProgram Counter

ICIntegerated Chip

EEPROMElectrically Erasable Programmable ROM

WDT Watch Dog Timer

POR Power On Reset

PWRTPower Up Timer

BORBrown Out Reset

UARTUniversal Asynchronous Receiver Transmitter

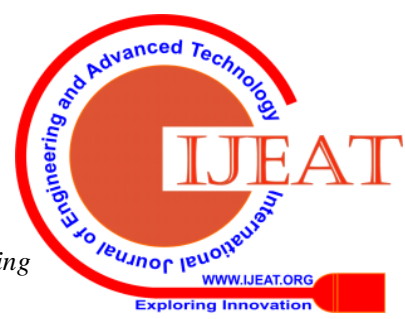




\section{CONCLUSION}

The data from the windmill can be received by the owner's mobile by sending valid codes. This project not only givesconvenience to the windmill operator but can also provide security to its production data. Since code is provided to receive alerts from the module. Windmills located in remote areas are not easily accessible. This was one of the issues has been solved. When the windmill is not in operation it will automatically sends the status to the owner's mobile, so the shutdown period is less. This gives the owner to access the windmill anywhere in the world using GSM technology. This provides a simple, convenient, time saving and secures system for monitoring the windmill power generation.

\section{REFERENCES}

1. M. A. Mazidi, "The 8051 Microcontroller \& Embedded Systems", Pearson Education Asia, India, 2nd edition, 2008.

2. Kenneth J. Ayala, "The 8051 micro-controller Architecture, programming \& applications", Penram International, India, 1996

3. Raj Kamal, "Embedded System- Architecture, Programming and Design", Tata McGraw Hill Publisher, 2nd edition, 2008

4. Myke Predco, "Programming and customizing 8051 microcontroller", Tata McGraw Hill

5. Nisi, K., B. Nagaraj, and A. Agalya. "Tuning of a PID controller using evolutionary multi objective optimization methodologies and application to the pulp and paper industry." International Journal of Machine Learning and Cybernetics (2018): 1-11.

6. http://www.wikipedia.org

7. http://www.atmel.com

8. http://www.simcom.com

9. http://www.howstuffworks.com. 